\title{
Derecho Aplicable a la Contratación y el Arbitraje Internacional
}

\author{
José Antonio Moreno Rodríguez ${ }^{1}$
}

\begin{abstract}
Sumario
1. En general. 1.1 Autonomía de la voluntad. 1.2 Aplicabilidad del derecho transnacional o lex mercatorin. 1.3 Instrumentos de la lex mercatorin. 1.4 Elección del derecho por el tribunal arbitral. 1.5 Método directo. 1.6 Lex mercatoria en ausencia de voluntad de las partes. 1.7 Ex aequo et bono y amiable composition. 1.8 Usos mercantiles aplicables al caso. 2. Conclusión.
\end{abstract}

\section{EN GENERAL}

El problema del derecho aplicable a la contratación constituye uno de los puntos más debatidos en el arbitraje comercial internacional ${ }^{2}$, en el que existe el mayor cuerpo de precedentes arbitrales y que ha dado lugar al mayor número de casos de arbitrajes de la Cámara de Comercio Internacional, por ejemplo, en que se citan laudos previos ${ }^{3}$.

Debe considerarse que las lagunas, ambigüedades o divergencias interpretativas sobre el derecho aplicable -como bien lo

1. LL.M, Harvard. Sccretario General de la Asociación Americana de Derecho Internacional Privado. Micmbro del Working Group de la Conferencia de La Haya de Derecho Intemacional Privado en materia de derecho aplicable a la contratación.

2. Ver comentarios y advertencias en VAGTS, Detlev F. Arbitration and the UNIDROIT Principles. Contratación Intemacional. Comentarios a los Principios sobre los Contratos Comerciales Internacionales del UNIDROIT. Universidad Nacional Autónoma de México, Universidad Panamericana. México: 1998, p. 272.

3. CRAIG, Laurence, William PARK y Jan PAULSSON, International Chamber of Commerce Arbitration. 3ra edición. Nueva York: Occana Publications, 2000, p. 641. 
resalta YVES DERAINS- no solo complican la solución de eventuales controversias, sino pueden contribuir incluso a que aparezcan. Si las partes no saben cuál regla se aplica a su relación contractual, cada una de ellas, de buena fe, estará tentada a ejecutar el convenio conforme al derecho que conoce mejor (como, por ejemplo, el de su país) sin percibir que al hacerlo, está incumpliendo con sus obligaciones, dando pie, precisamente por ese hecho, al nacimiento de un conflicto. Por lo demás, una parte con mala fe puede tomar ventaja de cualquier incertidumbre relativa al derecho aplicable e intentar ceñirse al que mejor sirve sus propios intereses ${ }^{4}$.

Ya surgida la contienda, si las partes no lo hicieron, el derecho aplicable lo pueden determinar los árbitros en el laudo final, aunque -como señala WEBSTER- uno podría generalmente esperar que el tribunal trate la cuestión del derecho aplicable desde el vamos, por vía de un laudo parcial, para permitir que los afectados encaren el proceso conociendo la posición del tribunal en este punto5.

Esta contribución aborda algunas cuestiones fundamentales que se presentan con respecto al derecho aplicable a la contratación y el arbitraje internacional, como las relativas a autonomía de la voluntad, selección del derecho por el tribunal arbitral y aplicabilidad, en su caso, de la lex mercatoria o derecho transnacional (términos que utilizamos aquí de manera indistinta)6.

4. DERAINS, Yves. The ICC Arbitral Process. Part. VIII. Choice of the Law Applicabic to the Contract and Inicmational Arbitration. p. 10.

5. WEBSTER. Thomas H., Handbook of Uncitral Arbitration, Commentary, Precedents and Materials for UNCITRAL based Arbitration Rules. Sweet \& Maxwell, Thomson Reuters, 2010, p. 515.

6. La Icrminologia alusiva a la kex mercatoria es caótica. En las primeras décadas del siglo XX LAMBERT utilizaba la expresion "derecho corporativo intemacional" (droit comoratif intermationaf). JESSUP, en su obra Transnational Law de 1956, parece haber sido el primero en poner en circulación la expresión lex mercatoria, con la que se pretende superar la división tradicional entre el aspecto público y privado de las relaciones internacionales (ver RIGAUX, Françuis. Derecho Internacional Privado, Parte Gencral. Madrid: Civitas, 1985, p. 81). Modemamente la utilizan aulores como GOODE (GOODE, Roy. "Usage and lts Reception in Transnational Commercial Law". En: revista ICLQ. Cambridge: Cambridge University Press, 1997, p. 2), MUIR WATT(MUIR WATT, Horatia. New Challenges in Public and Private International Legal Theory: Can Comparative Scholarship Help.' Epistcmology and Mcthodology of Comparative Law: Van Hoccke, Mark (cd.). Hart Publishing. 2004, p. 277), Loussouarm, Boruel y Vareilles Sommières -quienes tambièn aluden a un 


\subsection{Autonomía de la voluntad}

Propagado a lo ancho del orbe ${ }^{7}$, el principio de la autonomía de la voluntad -entendido en las transacciones transfronterizas como la facultad de los contratantes para elegir el derecho aplicable y el tribunal estatal o arbitral que entenderá el caso-, tiene un atractivo muy poderoso, puesto que nadie se encuentra mejor posicionado que las partes para determinar el sistema jurídico que les rige, en vez de que lo hagan en su nombre, un legislador de antemano o un juzgador con ulterioridad, en su caso8.

Como lo destaca FernándeZ ARRoyo, el avance del principio de la autonomía de la voluntad, a expensas del de la soberanía otrora imperante, es característica de tendencias recientes en el Derecho internacional privado y promete una profundización en

"orden superior" (BOUREL. Pierte, Yvon LOUSSOUARN, Pascal VAREILLES-SOMMIĖRES. Droit international privé. 8e Edition. Éditions Dalloz, 2004, p. 3), entre varios otros. También se habla de un "derecho a-nacional", término atribuido a FOUCHARD (MUSTILL, Lord Justicc. The New Lex Mercatoria: The First Twenty-Five Years. Liber Amicorum for Lord Wilberforec. Clarendon Press. 1999, p. 15!, nota al pic), en tanto que los Principios de UNIDROIT de derecho contractual utilizan la palabra "supranacional". También puede verse en Berman la utilización de la expresión "world law" (dereche mundial) (BERMAN, Harold. J. Is Conflict-of-Laws Becoming Passe?, An Historical Response. Emory University School of Law, Public Law \& Legal Research Paper Series, Research Paper $n^{\circ}$ 05-42, http://papers.ssm com/abstract $=870455$ ) (último acceso: 31 te enero de 2011). Illescas y Perales Viscasillas, por su parte, en vez de utilizar expresiones como lex mercatoria, Derecho mercantil internacional, Derecho comercial internacional o Derecho del comercio internacional, se inclinan por adoptar - por considerarla más adecuada- la terminologia de Derecho uniforme del comercio intemacional (ILIESCAS ORTIZ, Rafacl, Pilar PERALES VISCASILLAS, Derecho Mercantit Internacional. El Derecho Uniforme. Editorial Centro de Estudios Ramón Areces, S.A.. 2003, pp. 28 y ss.). Actualmente se encuentran muy en boga las expresiones en inglés soft law, o derecho de génesis no-estatal y su contrapartida hard law, que si tiene dicho origen.

7. Ver al respecto en MORENO RODRIGUEZ, Josi Antonio. Los Contratos y La Haya ¿Ancla al pasado o pucnte al futuro? ¿Cómo se codifica hoy el derecho comercial internacional? BASEDOW, Jürgen/FERNANDEZ ARROYO, Diego P/MORENO RODRIGUEZ, Josí A. (dirs.) CEDEP y La Ley Paraguaya, 2010, p. 245.

8. Además de fortalecerse la seguridad juridica que deberia predominar en transacciones comerciales (VISHER, Frank. General Course on Private International Law. Recucil des Cours, Collected Courses of the Hague Acadcmy of Intemational Law, 1992, 1, Tome 232 de la colección, Martinus Nijhoff Publishers, 1993, p. 126; también pp. 132 y siguientes), ello tiene también un fin -resaltado por Jayme- de "desreglamentación", al disminuirse el dirigismo estatal para darse pie a iniciativas privadas (JAYME, Erik, Identite Culturelle et Intigration: Le Droit International Prive Postmoderne. Cours geineral de droit international prive. Recueil des Cours, Collected Courses of the Hague Academy of Intemational Law 1995, IV, Tome 251 de la colección, Martinus Nijhoff Publishers, 1996, pp. 150(51). 
los años venideros ${ }^{9}$, lo que de hecho viene ocurriendo - por ejemplo en Latinoamérica- con el dictado de numerosas leyes arbitrales, que consagran tanto la autonomía para recurrir al arbitraje internacional como para que las partes elijan el derecho aplicable a sus vinculaciones sometidas a eventual resolución por este medio ${ }^{10}$.

El arbitraje internacional tiene peculiaridades que lo distinguen claramente de litigios ante jueces nacionales, pues, en general, se ve reflejado allí el deseo de los afectados de evitar una solución "legalista" -por así decirlo- a sus conflictos mercantiles. Los comerciantes frecuentemente sienten que los tribunales ordinarios no entienden las realidades del intercambio comercial, y los árbitros, cuya misión originaria deriva del acuerdo de las partes, deberían -y generalmente lo hacen- dar prelación a las reglas que ellas mismas han establecido para sus vinculaciones, es decir, los términos del contrato y los usos, costumbres y prácticas que les sirven de marco.

No es de extrañar, pues, que la autonomía de la voluntad constituya uno de los ejes sobre los que se asienta la Convención de Nueva York de 1958 relativa a reconocimiento y ejecución de laudos arbitrales, propiciada por las Naciones Unidas y hoy día ratificada por más de ciento cincuenta países, lo que le ha merecido calificativos como los de Lord Mustill de ser "la más efectiva instancia de legislación en la historia del Derecho comercial"11, y de GOODE que la califica de "astonishingly succesful"12, en tanto que WETTER la considera el "pilar en el cual descansa el edificio del arbitraje internacional"13.

9. FERNÁNDEZ ARROYO, Diego P. Derccho intemacional privado (Una mirada actual sobre sus elementos esenciales). Editorial Advocatus, 1998, p. 92.

10. Ver MORENO RODRJ́GUEZ, Josí A. (nota 7), p. 245.

11. Ver cita en KRÖLL, Stefan, Julian D.M LEW, Loukas MISTELIS. Comparative International Commercial Arbitration. 2003. p. 694.

12. GOODE, Roy. The Role of the Lex Loci Arbitri in Intcrnational Commencial Arbitration. Arbitration Intcrnational. Vol. 17. 2001, n" I, p. 22.

13. KRÖLL, Stefan, Julian D.M. LEW, Loukas MISTEL,IS. (nota 10), p. 694. 
El principio también se desprende de instrumentos convencionales regionales, como las Convenciones de Panamá de 1975, sobre arbitraje comercial, y de Montevideo de 1979, sobre reconocimiento y ejecución de laudos, elaboradas dentro del seno de la Organización de los Estados Americanos (OEA) y ratificadas por varios países de la región; además -también dentro de la esfera de la OEA- de la Convención de México de 1994 sobre el derecho aplicable a la contratación internacional ${ }^{14}$, inspirada en el Convenio de Roma de 1980 (hoy Reglamento Comunitario $593 / 2008$, conocido como "Roma I") y, en el ámbito del Mercado Común del Sur (MERCOSUR), el Acuerdo sobre Arbitraje Comercial Internacional (Decisión Consejo Mercado Común $n^{\circ}$ $3 / 98$ ), ratificado por los cuatro miembros plenos del bloque ${ }^{15}$.

Pues bien, en consonancia con todos estos desarrollos, el artículo 28 de la ley modelo de la Convención de las Naciones Unidas para el Derecho Mercantil Internacional (en adelante CNUDMI), y las numerosas leyes dictadas en consecuencia, consagran el principio de la autonomía de la voluntad para la determinación del derecho aplicable al fondo del arbitraje. Lo propio hacen el anterior reglamento arbitral de la CNUDMI'16, como así

14. Ratificada en dos paises del continente (México y Venezuela) y aplaudida en prestigiosos circulos académicos regionales y mundiales, la Convención de México admite de manera amplia la autonomia de la voluntad, tanto para elegir como para modificar eventualmente el derecho aplicable, ademas de permitir que se seleccionen distinlos derechos que rijan parcialmente el acuerdo (dépeçage), lo cual -resalta Herbert-podria parecer una herejia en el esquema de los Tratados de Montevideo de 1889 y 1940 (HERBERT, Ronald. La Convención Interamericana sobre Derecho Aplicable a los Contratos Intemacionales. RUDAP, Año $1-n^{\circ} 1$, p. 91.). Pero la apertura autonomista de la Convención de México va más allá, al punto de facultarse a que las partes elijan èerechos "no nacionales", a la vez que se habilita al juzgador a recurrir al derecho transnacional, "soft law" o "lex mercatoria" (SIQUEIROS, José Luis. Los Principios de UNIDROIT y la Convención Interamericana sobre el Derecho Aplicable a los Contratos Internacionales. Contratacion Internacional, Comentarios a los Principios sobre los Contratos Comerciales Internacionales del UNIDROIT. Universidad Naciona! Autónoma de México, Universidad Panamericana, 1998, p. 222). E1 Convenio de Roma no habia resuelto esta cucstión, y connotados juristas csperaban que Europa siguiera el modelo americano, al que veian con simpatia como alternativa para modemizar el Convenio de Roma. Sin embargo, cl nuevo Reglamento Roma I tampoco avanza en st sentido de la Convención de México, por lo que solo valúrá, en su caso, la incorporación por referencia, "al menos en procesos ante tribunales cstatales", expresa HEISS, lielmut. Party Autonomy, Rome I Regulation, The Law Applicable to Contractual Obligations in Europe. FERRARJ, Franco/LEIBLE, Stefan (cds.). Sellier, 2009, p. 2.

15. Argentina, Brasil. Paraguay y Uruguay.

16. En la práctica, la mayoria de los casos de arbitraje son decididos en base a los términos del contrato. El derecho aplicable, que solo raramente juega un rol en la interpretación de dichos términos, tiene 
también el artículo 35 del actual reglamento y otros reglamentos arbitrales de instituciones preponderantes en el mundo, como el artículo 17.1 de las reglas de la Cámara de Comercio Internacional, el artículo 28.1 de la American Arbitration Associntion, el artículo 22.3 de la London Court of International Arbitration y el artículo 22.1 de la Cámara de Comercio de Estocolmo, inter alin. Debe tenerse presente que las reglas de las diversas instituciones arbitrales tienden a convergir guiadas, a su vez, por las soluciones elaboradas bajo los auspicios de la CNUDMI17.

Como señala el comentario al artículo 28 de la ley modelo, la consagración expresa en dicha ley de la autonomía de la voluntad es importante dado que varias leyes nacionales no reconocen clara o plenamente esa facultad. Ello ha motivado, por ejemplo, esfuerzos como el de la Conferencia de La Haya de Derecho Internacional Privado, que se encuentra actualmente evaluando un futuro instrumento en materia de derecho aplicable a la contratación internacional, uno de cuyos objetivos sea la promoción del principio de la autonomía de la voluntad en el mundo ${ }^{18}$.

sin embargo relevancia si el contrato calla en cuestiones como por cjemplo: tasas de interés, o si cl contrato existe o no como tal. Pues bien. este articulo 35 del reglamento, consagratorio del principio de la autonomia de la voluntad, fue redactado de manera que quede bien en claro que el contrato debe tener cstricta primacia (CARON, David, Lee M CAPLAN.,, Matti PELLONPÄÄ.. The UNCITRAL Arbitration Rules. A Commentary. Oxford University Press, 2006, pp. 136-137, quienes emiten el comentario en referencia a la redacción en inglés "in accordance with" adoptada en el primer reglamento de 1976).

17. BARCELÓ III, John, Arthur Taylor J.VON MEHREN, Tibor VARADY. International Commercial Arbitration, a Transnational Perspective. Fourth Edition. Thiomson Reuters, 2009, p. 70. Tambien BROWER, inter alia, hace notar la uniformidad cxistente en gran parte entre las reglas de las distintas instituciones arbitrales preponderantes en el mundo (BROWER. Charles N. W(h)ither Intemational Commercial Arbitration? The Goff Lecture, 2007, p. 184).

18. Pucde ampliarse al respecto en el sitio web de la Conferencia de La Haya de Derecho Intemacional Privado (htip:/www.hech.net) o, particularmente, en el siguiente link: http//www.hech net/index_en.php?act=Iext.display\&tid=-19 


\subsection{Aplicabilidad del derecho transnacional o lex mercatoria}

Se han señalado diversos supuestos en que resulta altamente inapropiado remitirse a derechos "nacionales", como el de una transacción tan internacional que no puede verse como influenciada exclusivamente por un sistema jurídico en particular, o cuando las partes, expresa o implícitamente, buscaron que su contrato sea gobernado por reglas juridicas neutras, no perteneciendo a un específico derecho nacional. Además, hay casos en que se debería evitar la aplicación de un derecho estatal, como cuando una de las partes es un Estado soberano o una entidad estatal. A veces, la elección de las partes es equivalente a la ausencia de elección de un derecho nacional, como en el caso en que se designó la legislación tanto de Alemania como de Rusia. Otras veces, es imposible determinar, dentro del derecho nacional supuestamente aplicable, una solución específica al caso. También existen precedentes en los que los árbitros aplicaron el derecho transnacional o lex mercatoria para llenar un vacío, o para interpretar el derecho nacional, o para reemplazar el derecho nacional elegido por las partes en base a la teoría del orden público internacional ${ }^{19}$.

Por lo demás, si bien es cierto que las partes pueden someter sus vinculaciones contractuales a una regulación detallada, conforme a su autonomía privada, al hacerlo se encuentran con enormes dificultades de barreras del lenguaje y de ausencia de una terminología jurídica uniforme a nivel internacional. Incluso la elección de un derecho doméstico no es solución satisfactoria. A veces, ello ocurre debido a razones de prestigio o imperativo político, en que una parte no quiere someterse a la normativa de un país extranjero aun consciente de las limitaciones de su propia legislación. El problema es mayor aún cuando no se conoce bien la legislación extranjera o no se la desea por completo20.

19. RUIZ ABOU-NIGM. Verónica. The Lex Mereatorin and Its Curtent Relevance in Intemational Commercial Arbitration. Revista DeCITA. Derecho del comercio internacional, temas y actualidades, DREYZIN, Adriana/FERNANDEZ ARROYO, Diego (dirs.). Arbitraje, 02.2004, pp. 109-110.

20. BONELL, Michael Joachim. The Unidroit Principles of International Commercial Controcts, Nature, Purposes and First Experiences in Practice. www. unidroit org, p. 2. (Ültimo acceso: 31 de enero de 2011). 
Varios reglamentos arbitrales dan pie a la aplicación del derecho transnacional o lex mercatoria ${ }^{21}$, en sintonía con trascendentes cuerpos normativos, partiendo de la propia Convención de Nueva York de 1958, que no solo facilitó la propagación -cual reguero de pólvora- del arbitraje en el mundo, sino también abrió las compuertas al derecho transnacional. Es así que, según una interpretación prevaleciente con respecto a este instrumento,

"...el hecho de que un árbitro internacional haya sustentado un laudo en normas transnacionales (principios generales del derecho, principios comunes a muchos derechos, derecho internacional, usos del comercio y expresiones análogas), en vez del derecho de un Estado determinado, no debería, por sí mismo, afectar la validez o el carácter ejecutorio del laudo, cuando las partes acordaron que el árbitro aplicaría normas transnacionales, o cuando las partes guardaron silencio respecto al derecho aplicable ${ }^{\prime 22}$.

Al éxito de este texto convencional debe sumarse el aggiornamento en los derechos internos, más aún luego de que la ley

21. Zanjando asi la controversia existente en el plano térico, al menos en lo que respecta a la aplicabilidad de la Iex mercatoria a los arbitrajes. Quienes se oponen al Derecho supranacional, derivado del arbitraje, sostienen que la creación del derecho (law-making) constituye, exclusivamente, una funciỏn politica del Estado, cjercida a través de instituciones legislativas y judiciajes. Según csta posición. árbitros designados por particulares, carenies de mandato público alguno y contratados para un único caso, no pueden adoptar determinaciones con fucrza juridica. Incluso cuando el Estado interviene para revisar un fallo arbitral, ello continua siendo consecuencia de una opción contractual de particulares. Y, cuando el fallo es cjecutado coactivamente en la esfera judicial, el resultado y el razonamien10 -si existe alguno- que subyace en la decisión no constituyen fuente del derecho. En estos casos, el Estado meramente ratifica las decisiones de los árbitros como reconocimiento o tolerancia al derecho contractua! de las partes de comerciar y de someter su relación mercantil al arbitraje. Desde otra perspectiva, quienes defienden el derecho supranacional o Irasnacional configurado a través de la prictica arbitral sostienen que, a pesar de su origen privado, puede progresivamente adquirir la fucrza de norma juridica. En la órbita del comereio internacional, los Estados implicitamente han delegado su potestad creadora de derecho (law-making authority) a árbitros y a un proceso de resolución de conflictos privados admitido internacionalmente. Ello ha ocurrido particularmente en los paises que han adoptado la ley modelo de arbilraje de la CNUDMI o regulaciones en esa misma linea. Los Estados han pucsto en vigencia leyes que promueven la desregulación del arbitraje, actúan como venia hospitalaria para que se lleven adelante arbitrajes y para la ejecuciỏn de fallos arbitrales, bajo un muy limitado cscrutinio judicial. La conducta del Estado ha legitimado el procedimiento y la autonomia jel arbitrajc (ver CARBONNEAU, Thomas. The Remaking of Arbitration: Design and Destiny. Lex Mercatoria and Arbitration, A Discussion of the New Law Merchant. Revised Edition. Juris Publishing. Kluwer Intcrnational Law, 1998, p. 12).

22. Declaración de la Conferencia de El Cairo del Instituto de Derecho Intemacional, de 1992, alusiva a la Convención de Nueva York (citada en MORENO RODRiGUEZ, José A.; ver nota 7). 
modelo propiciada por la CNUDMI en 1985, haya inspirado reformas normativas por doquier, para volver más propicios los sistemas nacionales a las peculiaridades del arbitraje. Esta ley no solo tiene como uno de sus pilares el principio de la autonomía de la voluntad, sino también habilita a que las disputas sean resueltas de acuerdo a principios y criterios transnacionales, cuando las partes así lo hayan decidido. Al efecto, el artículo 28 de la ley modelo utiliza la expresión "normas de derecho23, que debe entenderse equivalente a lex mercatoria o derecho transnacional24.

En la misma línea, muestran una amplia apertura hacia el derecho transnacional los reglamentos de la CNUDMI 25 y de las principales instituciones arbitrales del mundo ${ }^{26}$. Este constituye un dato no menor, si se considera la uniformidad existente entre

23. Hasta su inclusión en la lcy modelo, la expresión "normas de derecho", alusiva al derecho transnacional, solo habia sido utilizada en el articulo 42 del Convenio de Washington de 1965 relativo a disputas de inversiones $y$ en las leyes de arbitraje de Francia y Djibouti (Documento UNCITRAL A/CN.9/WG.JI/WP.143/Add.1).

24. El comentario de UNCITRAL al articulo 28 de la ley modelo expresa que al hacer referencia a la clección de las "normas de derechio" y no a la "ley", ta ley modelo brinda a las partes una gama de opciones mis amplia en lo tocanic a la indicación de la ley aplicable al fondo del litigio, por cuanto aquellas pueden, por ejemplo, elegir de común acuerdo nosmas de derecho claboradas por un organismo internacional pero no incorporadas aún a ningún ordenamiento juridico nacional. Destaca GRIGERA que en Derecho internacional privado, el término "derecho" (o "lcy", a secas) para referirse al régimen juridico aplicable al fondo de la controversia en materia de arbitraje internacional se entiende que excluye normas, principios o reglas de fuente a nacional o internacional general, y se limita tan solo a los derechos nacionales o convenciones intemacionales ratificadas por los Estados cuyas condiciones de aplicación se encuentren reunidas en el caso conereto (GRIGERA NAÓN, Horacio A. El Acucrdo sobre Arbitraje Comercial Iniernacional del MERCOSUR: un Análisis Critico. Revista Brasileira de Arbitragem, Coedición de Sintese y el Comité Brasileiro de Arbitragem, 2003. n" I, p. 24). A su vez, se expresa en los Principios Europeos de Derecho Contractual: "La expresión normas de derecho' del art. 28(1) de la ley modelo supone que las partes pueden escoger la lex mercatoria para regir su contrato (Notas, art. 1:101 PECL, comentario 3, a)".

25. Se lee en los documentos oficiales preparatorios de la CNUDMl (A/CN.9/WG.II/WP.151/Add.1 y A/CN.9/WG.11/WP.149), que en las discusiones en tomo al borrador del actual articulo 35 (articulo $33 \mathrm{cn}$ el Reglamento de 1976), el Grupo de Trabajo concordó que el tribunal arbitral deberia aplicar las "normas de derecho" designadas por las partes y, consecuentemente, esta expresión deberia reem. plazar la palabra "Icy" en la primera oración del articulo 33 (A/CN.9/641, para. 107). La expresión sc entiende más amplia que el término "Iey", $\mathrm{y}$ permite a las partes designar como aplicable a su caso las reglas de más de un sistema juridico, incluyendo reglas que pudieron haber sido claboradas en un plano internacional.

26. Como el de la CNUDMI, la Cámara de Comercio Internacional (CCl), la American Arbitration Association (AAA); la London Court of International Arbitration (LCIA); la Cámara de Comercio de Estocolmo; el Centro de Disputas de la Organización Mundial de la Propiedad Intelectual (OMPl); y el Centro de Resolución de Disputas en Materia de Inversiones del Banco Mundial, cuya abreviatura en español cs la de CIADI. 
estos instrumentos normativos, con el efecto homogeneizador consecuente.

Esta apertura hacia el derecho transnacional se reafirma con la adhesión masiva al Convenio Constitutivo del Centro Internacional de Arreglo de Diferencias Relativas a Inversiones (CIADI en español o ICSID en inglés), creado en Washington en 1965, de gran amplitud hacia el derecho transnacional; como así también al Convenio Constitutivo del Organismo Multilateral de Garantía de Inversiones (MIGA) de Seúl, Corea, que garantiza la ejecución, en los países adherentes, del laudo arbitral en materia de inversión dictado de conformidad con sus normas ${ }^{27}$; además de otros textos convencionales como los propiciados en el ámbito de la OEA y del MERCOSUR. Todos estos instrumentos se muestran propicios a la aplicación del derecho transnacional28.

A lo que debe sumarse el imponente desarrollo casuístico, sobre todo en las últimas décadas en que, además, los laudos arbitrales comenzaron a ser publicados y -por ende- difundidos internacionalmente ${ }^{29}$. La Cámara de Comercio Internacional, por ejemplo, difunde sus laudos desde 1974 en el "Journal du droit international", los que, a partir de entonces, también aparecen en otras publicaciones. Estos laudos, por su parte, citan o se apoyan en muchos casos en otros anteriores.

27. LEATHLEY, Cliristian International Dispute Resolution in Latin America. An Institutional Overview, Kluwer Law Intemational, 2007, p. 25.

28. Asi, el convenio constitutivo del CIADI prevé en su articulo 42, que "podrán tener virtualidad las normas de derecho internacional que pudieren ser aplicables". Ello en tanto que la Conveneión de Panama de 1975 se remite, en su articulo $3^{\circ}$, a falta de acuerdo entre las partes, a las reglas de procedimiento de la Comisión Interamericana de Arbitraje Comercial (CIAC), cuyo Art. 30 prevé, a su vez. que en todos los casos se tendrain en cuenta "los usos mercantiles aplicables". Por su parte, los acuer-

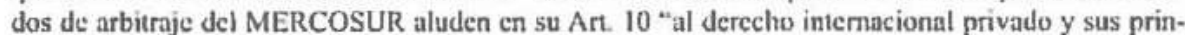
cipios, asi como al derecho del comercio internacional". Ello surge también del Art. 25, inciso $3^{\circ}$,

29. Con el debido resguardo de la confidencialidad que impone la materia arbitral, lo cual implica por lo general la no mención de las partes y de ciertos hechus relativos a los casos que se publican. Ello a pesar de que muchas decisiones no contienen razonamiento (solo expresan quièn ganó y quién perdió) y otras tantas no son publicadas (ver KUPFER SCHNEIDER. Andrea, Carric MENKEL-MEADOW, L.ela JPORTER LOVE, Jean R. STERNLIGHT. Dispute Resolution, Beyond de Adversarial Model. Aspen Publishers, 2005, p. 453). 
A su vez, los laudos arbitrales han sido sistematizados por la doctrina, a cuyo respecto, claramente, los juristas franceses han estado a la vanguardia ${ }^{30}$. Esa doctrina, nuevamente, recibió espaldarazos importantes de altos tribunales de diversas jurisdicciones claves para el desarrollo del comercio internacional ${ }^{31}$.

Pero la cosa no para allí. En paralelo a la resurrección, en forma moderna, de la lex mercatoria en el arbitraje, se propugna incluso la liberación del proceso arbitral, y de su eventual laudo, de los derechos nacionales, con lo que la contienda por esta vía debería ser capaz de "flotar" independientemente al país en que se conduce, produciéndose así lo que se llama como "deslocalización" o "desnacionalización". Se sostiene incluso que las leyes nacionales solo tendrían efecto, en su caso, ante un ulterior estadio de ejecución del laudo en virtud de limitadas eventuales causales de invalidación o-por supuesto-, cuando las partes específicamente designan el derecho del foro arbitral (lex loci arbitri) como aplicable al procedimiento arbitral. Si bien debe reconocerse que la deslocalización del arbitraje -en palabras de FERNÁNDEZ ARROYO- constituye una tendencia y no un hecho consumado ${ }^{32}$, hasta detractores como Goode han llegado a reconocer que el debate ha ayudado a la formulación de principios internacionales ${ }^{33}$.

30. Debido al influjo de la doctrina francesa, algunos criticus han llegado a afirmar que se está ante un "fantasma creado por profesores de la Sorbona" (TEUBNER, Gunther. Breaking Frames: The Global Interplay of Legal and Social Systcms. Amcrican Joumal of Comparative Law. 1997 (45 Am. J. Comp. L. 149), p. 151). En general, ver MORENO RODRIGUEZ, José Antonio. Nueva Lex Mercatoria: Fantasma creado por profesores de La Sorbona? Foro de Derecho Mercantil, Revista Internacional. Editorial Legis: 2003, $\mathrm{n}^{\circ}$ 1). Ello en alusiön a Goldman y otros juristas franceses que instalaron el debate contemporáneo en torno al derecho transnacional asi manifestado (ver, por ejem. plo, GOLDMAN, Berthold en Lex Mereatoria and Arbitration. A Discussion of the New Law Merchant, Carbonneau, Thomas E. (ed.), Revised Edition, Juris Publishing, Kluwer International Law, 1998).

31. Ver MORENO RODRIGUEZ, Josć A. (nola 7).

32. FERNÁNDEZ ARROYO, Diego P., Los Dilemas del Estado Frente al Arbitraje Comercial Internacional, en Revista Brasileira de Arbitragem, Año II. No. 5, IOB Thomson y Comité Brasilciro de Arbitragem, 2005, p. 117.

33. GOODE, Roy. (nota 11), p. 22. Por eso, se ha cxp̧resado que los laudos franceses y americanos levantan "policy concerns" que han dividido a la doctrina (CRAIG, Laurence, William PARK, Jan PAULSSON. (nota 3), p. 685). Para los argumentos a favor y en contra de la deslocalización, puede verse un muy buen resumen en MORENO RODRIGUEZ ALCALÁ, Roberio. Delocalizaciön, la lex loci arbitri y la nucva Ley de Arbitraje y Mediaciön. Arbitraje y Mediación, MORENO RODRIGUEZ, José A. (coord.). Intereontincntal Editora, 2003, pp. 64-171. 
De modo que, de la praxis arbitral ${ }^{34}$, renace -o se extiende en su consolidación- un derecho consuetudinario universal como lo fue el de los mercaderes en la Edad Media, al punto incluso de que organismos internacionales han propuesto su cristalización en cuerpos normativos como convenciones, guías legislativas, leyes modelo $u$ otros instrumentos análogos, o bien han ensayado consolidarlo en documentos peculiares como "Restatements" o "Principios" 35 .

\subsection{Instrumentos de la lex mercatoria}

Diversos textos, algunos destinados a obtener sanción estatal y otros no, han contribuido a consolidar el renacido derecho transnacional o lex mercatoria.

De suma trascendencia resulta la Convención de Viena sobre compraventa internacional de mercaderías de 1980, elaborada por la CNUDMI, que reúne en un texto convencional de derecho uniforme principios, reglas, usos y costumbres aplicables al contrato preponderante del comercio internacional ${ }^{36} . \mathrm{Si}$

34. Hace unos años, una investigación cncabczada por Berger recurtió a una encuesta cntre 2.733 abogados. De quienes respondieron, aproximadamente un tercio indicó que estaban al tanto de al menos un caso ocurrido en su práctica en que las partes han referido al derecho transnacional en sus contratos, y más del $40 \%$ estaba al tanto de al menos un procedimiento arbitral en que se utilizó el término (ver en DRAHOZAL, Christopher R. Of Rabbits and Rhinoceri: A Survey of Empirical Research on Intemational Commercial Arbitration. Joumal of International Arbitration, Vol. 20, $\mathrm{n}^{\circ} .1, \mathrm{p} .30$ ). Una reciente investigación, para la que -como lo refiere Mistelis-se utilizaron 136 extensos cuestionarios y datos cualitativos basados en 67 entrevistas a profundidad, señala que cl uso ofel derecho transnacional es razonabiemente común en la praxis arbitral (aproximadamente el $50 \%$ de los encuestados lo usaron al menos "a veces"). Otras conclusiones interesantes son que la elección del derecho aplicable está mayormente influeneiada por la percibida neutralidad e imparcialidad del sistema juridico con respecto a las partes y su contrato, lo apropiado del derecho para el tipo de contrato y la familiaridad de las partes con el derecho. Tambićn se concluye que la decisión sobre el derecho aplicable es una cuestión compleja en que, la mayoria de los que respondieron y fucrun entrevistados, parecicron tomar un considerado y bien pensado enfoque. En cuanto a los derechos nacionales, el $40 \%$ de los respondientes utilizaron el derecho inglés más frecuentemente, seguidos del $17 \%$ que recurrieron al derecho de Nueva York. El $53 \%$ de quienes respondieron ereen que el impacto del desecho aplicable puede ser limitado en alguna medida con un contrato meticulosamente redactado, y el $29 \%$ cree que puede ser limitado en una gran medida de esta forma (2010 Internationa/ Arbitration Survey: Choices in Intcrnational Arbitration, Quecn Mary, University of London, School of Intemational Arbitration (SlA) y White \& Case, pp. 11 y ss).

35. Puede profundizarse al respecto en: MORENO ROGRIGUEZ, José A. Nucva Lex Mercatoria. ¿Fantasma creado por profesores de La Sorbona? Revista de Derecho Mercantil Internacional. Editorial Legis, 2003. 
bien hoy por hoy, la Convención de Viena rige en más de setenta países, ella podría aplicarse aun sin estar ratificada, como expresión del status del derecho transnacional o lex mercatoria en la materia allí comprendida, en su caso.

Yendo más allá de la elaboración de textos destinados a tener sanción estatal, particular repercusión mundial ha tenido también la labor, en materia contractual, de UNIDROIT. Tal constituye el acrónimo francés de un instituto intergubernamental con sede en Roma, vinculado a Naciones Unidas a través de un acuerdo de cooperación, que publicó en los años 1994 y 2004 "Principios" de Derecho Contractual ${ }^{37}$ Grupos de expertos han trabajado para detectar y reformular (to restate) los "principios" universales en la materia, y los trabajos resultantes se encuentran consignados en textos con redacción parecida a la de las normas legislativas, acompañados de comentarios y ejemplificaciones, además de un preámbulo que precede y explica el instrumento ${ }^{38}$. Entre varias aplicaciones, estos principios pueden ser adoptados por las partes como reglas en sus contratos, o servir como guías a legisladores, jueces o árbitros en lo que respecta al status de los usos y principios internacionales ${ }^{39}$, y así viene ocurriendo de manera reiterada en tiempos recientes ${ }^{40}$.

36. Ver GARRO, Alcjandro, Albero L. ZUPPI. Compraventa internacional de mercaderias. Ediciones La Rocea, 1990, pp. 43 y ss.

37. Puede profundizarse al respecto en: MORENO RODRIGUEZ, José A. Los Principios Contractuales de UNIDROIT: ¿Un Mero Ejercicio Académico de Juristas Notables? Revista Foro de Derceho Mcrcantil. Editorial Legis, 2005; se reproduce asimismo en MORENO RODRIGUEZ, José A. Temas de Contratación Internacional, Inversiones y Arbitrajc, Catena Editores, CEDEP, 2006.

38. Ello al igual que los llamados "Restatements" norteamericanos, de elaboración académica, no destinados a obtener sanción cstatal-aunque si pucden inspirar reformas normativas-que resumen asi las tendencias preponderantes en diversos temas.

39. FARNSWORTH, en su análisis de diversos precedentes arbitrales, concluye que en ellos los árbitros realmente consideran los Principios de UNIDROIT como expresiön de los principios generales del derecho mercantil internacional o de la lex mercatoria, si asi se quiere llamarlos. En el boletin de la Asociación Suiza de Arbitraje aparece un estudio cn el cual se concluye que los prácticos frecuentemente tienden a evitar el término lex mercatoria y preficren referirse a los Principios de UNIDROIT. En los Estados Unidos, la expresión lex mecatoria tiende a conjurar imágenes de extrañas coneepeiones del civil law, lo cual explica por qui en paises del common law en general, y los Estados Unidos en particular, la gente se siente más cómoda teniendo a su disposición Prineipios como los de UNIDROIT. A diferencia de la lex mercatoria, refiere FARNSWORTH, uno puede asir los Principios de UNIDROIT en sus manos, por asi decirlo (FARNSWORTH, E. Allan. The Role of the UNIDROIT Principles in Intemational Commercial Arbitration (2): a US Perspective on their Aims and Application. Special Supplement 2002, ICC Intemational Court of Arbitration Bulletin, p. 22). 
En el seno de la Unión Europea se publicaron también "Principios" similares en los años 1995 (parte I), 1999 (partes I y II) y 2003 (parte III) (en adelante "PECL")41, elaborados por un grupo cuya cabeza visible fue el profesor escandinavo Ole Landö (Comisión Landö) y a partir del año $2003^{42}$ aparece en escena el "enigmático" concepto del Marco Común de Referencia (MCR)43. Tanto UNIDROIT como la "Comisión Landö", de manera imprecisa, habían denominado finalmente "principios" a su producto, cuando en realidad estamos ante un cuerpo de reglas que podrian fácilmente ser sancionados por un legislador como "Código". Esto fue enmascarado ahora bajo la expresión "Marco Común de Referencia”, que fue elegida por la Comisión europea ${ }^{44}$, y se espera contar como resultado final con Principios Comunes del Derecho Contractual Europeo (Common Principles of European Contract Latv-CoPECL), con definiciones de términos contractuales y con principios fundamentales y reglas coherentes en la materia ${ }^{45}$.

En la órbita privada se registran un sinfín de iniciativas, entre las que se destacan, a nivel mundial, los trabajos de la Cámara de Comercio Internacional ${ }^{46}$, que propone numerosos instrumentos normativos para que los particulares, haciendo uso de la libertad contractual, los incorporen a sus convenios, como ocurre por ejemplo con las reglas relativas a INCOTERMS (que aluden a términos estándares de intercambio usados en el

40. En UNILEX, Base de Datos del Centro para Estudios Comparativos e Internacionales, se cncuentran numerosas contiendas arbitrales -y judiciales-donde se recurre a los Principios de UNIDROIT (ver base de datos www.unilex info).

41. A nivel estatal, Ia Camara de los Lores de Inglaterra ha sido ta pnmera corte europea en citar los PECL, ya en el año 2001 (Director General of Fair Trading v First National Bank) (ver VON BAR, Christian. Comparative Law of Obligations: Mcthodology and Epistcmology. Epistemology and Methodology of Comparative Law, VAN HOECKE, Mark (ed). Hart Publishing, 2004, p. 126).

42. La idea de dicho MCR fue introducida por $\operatorname{COM}$ (2003) 68 final, 12 de febrero de 2003, paraigrafos 58.68,

43. VV. AA. The Common Frame of References for Europtan Private Law - Policy Choices and Codification Problems. Oxford Journal of Legal Studics N.N., Forthcoming. Disponible en SSRN: http://ssrn.com/abstract=1269270, encro 31, 2010, p. 4.

44. El modelo de todos es el de los Restatements norteamericanos (ver VV.AA. (nota 67), p. 12.

45. http://www.copecl.org (Ültimo acceso: 31 de enero de 2011).

46. Organización no gubernamental con sede en Paris, que cuenta con más de 7.000 miembros en 130 paises http:/www.iecwbo org (Último acceso: 31 de enero de 2011) 
comercio internacional ${ }^{47}$ ), a cartas de crédito documentarias ${ }^{48}$, etcétera ${ }^{49}$.

Existen también contratos estándares aceptados dentro de determinados círculos económicos, como las condiciones de contratos internacionales para la construcción de obras de ingeniería civil del año 1987, elaboradas bajo auspicio de la Federación Internacional de Ingenieros-Consejeros (FIDIC), conocidas comúnmente como Contrato FIDIC 50 ; o los formularios estándares internacionales de la Grain and Feed Trade Association con respecto a productos agrícolas, también de gran utilización en el comercio exterior ${ }^{51}$. Contratos modelos son también propuestos por organizaciones intergubernamentales y no gubernamentales, como el de venta internacional de bienes perecederos del UNCTAD/WTO International Trade Centre ${ }^{52}$, en tanto que el Banco Mundial53 y organismos de financiación europeos ${ }^{54}$ cuentan con lineamientos (guidelines) a este respecto.

A ello deben sumarse los llamados "Códigos de Conducta", elaborados en círculos privados -o también en organismos intergubernamentales ${ }^{55}$, que reúnen de manera sistemática normas generalmente de carácter programático, y tienen como carácterísticas su flexiblidad, el cumplimiento voluntario de sus postu-

47. Como FOB (Free on board-libre a bordo), CIF (Cost, insurance and ficight-Costo, seguro y flete), ctcétcro.

48. Las reglas uniformes para el uso de cartas de créditos documentarias, publicadas en cl año 2007 como UCP 600, fueron apoyadas por UNCITRAL en julio de 2007 (Informe de la Comisión sobre la labor realizada en su $42^{\circ}$ periodo de sesiones (A/64/17), 2009, paras. 356-357 http://www.uncitral.org).

49. Otro organismo privado muy influyente en su área es el Comité Maritimo Internacional (IMC en inglés, CMl en francés y español). htıp://www.comitemaritime,org' (Último acceso: $31 \mathrm{de} \mathrm{encro} \mathrm{de}$ 2011)

50. Ver www. fidic.org. (Úłtimo acceso: 31 de enero de 2011)

51. Ver www.gafla.com. (Último acceso: 31 de enero de 2011)

52. KRONKE, Herbert. The Scope of Party Autonomy in Recent UNIDROIT Instruments and the Conflict of Laws in the MERCOSUR and the European Union. Liber Amiconum en Homenaje al Profesor Didier Operti Badán. Editorial Fundaciön de Cultura Universitaria, 2005, p. 296.

53. Ver www.bancomundial.org (Ủltimo acceso: 31 de encro de 2011)

54. Ver www,curd.com (Último acceso; 31 de enero de 2011)

55. Asi, la Comisión de la Unión Europea, por Recomendación 77/524/CE de 1977, ha dictado el Código de Conducta Europeo relativo a transacciones de valores mobiliarios (ver sobre todo esto en FERNẢNDEZ ROZAS, José Carlos. Jus mercatorum, Autorregulaciön y unificación del Derecho de los negocios transnacionales. Editorial Colegios Notariales de España, 2003, pp. 91-198). 
lados y la autorregulación, al margen de normativas estatales. Aquí también la Cámara de Comercio Internacional cuenta con instrumentos como el International Code of Advertising Practice ${ }^{56} \mathrm{y}$ el International Code of Sales Promotion ${ }^{57}$; en tanto que la Factors Chain Internacional ha elaborado el Code of International Factoring Customs (IFC) 58 .

Los gremios de abogados, como la International Bar Association (IBA), la American Bar Associntion (ABA) 59 y la Union Internationale de Avocats (UIA)60, participan activamente, asimismo, en los diversos procesos de homogeneización, enviando sus representantes a los grupos de trabajo, además de proponer reglas privadas, como las reglas de ética, conflictos de intereses y producción de pruebas en el arbitraje de la IBA, de amplia utilización en el mundo ${ }^{61}$.

\subsection{Elección del derecho por el tribunal arbitral}

Señala BLESSING que la omisión de elegir expresamente el derecho aplicable puede ocurrir por varios motivos, como por ejemplo, el olvido de las partes; o porque estas no consideraron necesaria la elección; o porque los contratantes lo han discutido pero no llegaron a un acuerdo; o porque las partes han evitado intencionalmente discutir la cuestión, por ejemplo, porque sabrían que sería difícil llegar a un acuerdo o porque el miedo de discutir este tema impediría la conclusión del contrato ${ }^{62}$.

56. Ver

http://www.iccwbo.org/uploadedFiles/ICC/policy/marketing/pages/Spanish\%201CC\%20Consolidated $\% 20$ Code $\% 20$ on $\% 20 \mathrm{MA} \% 20$ Practice pưf (Ülimo acceso: 31 de enero de 2011).

57. Ver http://www icewbo.org/id502/index html (Ultimo acceso: 31 de enero de 2011).

58. http//www. factors-chain,com/ (Úlitimo acceso: 31 de encro de 2011).

59. http://www ibanct.org/ (Último acceso: 31 de enero de 2011).

60. http://www uianct.ory/ (Úlimo acceso: 31 de enero de 2011).

61. Se accede a través del siguiente link: http:/wwwibanct.org/Publications/publications_IBA_guides_and_free_matcrials aspx.

Asi tambièn, el Club Español de Arbitraje, por ejemplo, cuenta con Recomendaciones Relativas a la Independencia e Imparcialidad de los Árbitros, ademis de un Código para las Bucnas Prácticas Arbitrales (www clubarbitraje.com). (Último acceso: 31 de enero de 2011) 
Cuando las partes no han elegido el derecho de fondo, el artículo 28(2) de la ley modelo hace alusión a la aplicabilidad de "la ley que determinen las normas de conflicto"63, expresando el comentario de la CNUDMI que aquí las atribuciones del tribunal arbitral se ajustan a pautas más tradicionales. Es decir, en caso de silencio de las partes, el tribunal arbitral debería determinar como derecho aplicable uno de origen estatal, y no, por ejemplo, principios como los de UNIDROIT.

El sistema tradicional "conflictualista" ha presentado múltiples complicaciones en materia arbitral. La tendencia original reflejada en los laudos era la de otorgar prevalencia a las reglas de conflicto del lugar del arbitraje. Actualmente no existe consenso, pero hay tres alternativas que emergieron de la praxis y de recomendaciones doctrinarias: Primero, la aplicación acumulativa de las reglas de conflicto de todos los Estados que tienen conexión con las partes en disputa. Segundo, derivar estas normas de fuentes no nacionales, como principios del derecho o reglas de conflicto establecidas en convenciones internacionales. Tercero, aplicar otras normas, como las de la nacionalidad del árbitro, o del Estado cuyos tribunales hubieran tenido jurisdicción de no haberse pactado el arbitraje, o del Estado en donde se ejecutará el acuerdo64.

En lo que respecta a los casos de la Cámara de Comercio Internacional, destacan CRAIG, PARK Y PAULSSON, que el sistema de la aplicación acumulativa de reglas conflictuales relacionadas con la disputa es el más frecuentemente utilizado por los árbitros, que deben realizar un proceso comparativo para deter-

62. En algún momento el tribunal debiera preguntarse ¿si las partes tuvieran que convenir a qué derecho sujetarse, cuál elegirian? En la mayoria de los casos la conclusión debiera ser-según BLESSING que ni una de las partes querría someterse al derecho de la otra. Esto es lo que se conoce como "implied negative choicc" (BLESSING, Marc. Choice of Substantive Law in Interiational Arbirration. http://www.kluwerarbitration.com/document.aspx? id =IPN8666\&query=AND(content: $\% 22$ marc $\% 22$, content: $\% 22$ blessing $\% 22$, content: $\% 22$ choice $\% 22$,content: $\% 220 f \% 22$,content:\%22substantive \%22, content:\%22law\%22), (Ültimo acceso: 31 de enero de 2011).

63. Prevé la disposición: " "..2) Si las partes no indican la ley aplicable, el tribunal arbitral aplicará la ley que determinen las normas de conflicto de leyes que estime aplicables..."

64. Ver BORN, Gary B. International Commercial Arbitration, Comententary and Materials. Second Edition. Transnational Publishers Inc. and Kluwcr Law International, 2002, p. 530. 
minar si hay colisión o no entre estos sistemas. Los árbitros introducen así un elemento transnacional al proceso, al asegurar a las partes que la cuestión no quedará zanjada con la aplicación miope del sistema jurídico de un Estado en particular ${ }^{65}$.

Alternativamente, la aplicación que se haga de "principios generales" en materia de conflicto de leyes también envuelve un enfoque comparativo, pero - se ha dicho- con menos atención a la conexión entre esas reglas y la relación contractual en disputa ${ }^{66}$. A dicho efecto, se suele recurrir a convenciones internacionales, como ocurre frecuentemente con el Convenio de Roma de 1980 sobre el derecho aplicable a los contratos internacionales (hoy convertido en el Reglamento Comunitario Roma I)67, sean o no las partes destinatarias de dicha regulación 68 .

65. CRAIG, Laurence, William PARK, Jan PAUL.SSON. (nota 3), pp. 326-327.

66. CRAIG, Laurence, William PARK, Jan PAULSSON. (nota 3), p. 327.

67. Igual aplicación podria tener la Convenciön de México de 1994. Ella prevé que, en defecto de elección o en supuestos de ineficacia de csta selección, el contrato se regira por el derecho del Estado con el cual tenga los "vinculos más estrechos" (Articulo 9), con lo que se adopta la förmula flexible de "conexión más cercana o significativa" y se descartan otras nociones controvertidas. Se ha scrialado la bondad de esta solución, especialmente para situaciones en que las partes no tuvieron buen asesoramiento jurídico o estaban equivocadas con respecto al alcance del derecho elegido, con io que queda favorecida la búsqueda del derecho que mejor se adecua a los objetivos de los contratantes. E incluso, la disposición pucde funcionar en muchos casos como regla de validación para situaciones en que la elección del derecho derivaria en la ineficacia del contrato, en tanto que dificilmente las partes pudieron haber pretendido que el acuerdo no tuviera validez. La Convención de México desecha establecer pautas para determinar una "prestaciỏn caracteristica" que lleve al derecho aplicable, conforme lo hacia entonces su fuente curopea. El conceple de "prestación caracteristica" ha sido calificado por Juenger de "Nudo Gordiano". por volverse sumamente dudoso en permutas, contratos de distribución y en general en vinculaciones complejas, como lo son normalmenle las de la contralación internacional. Peor aún, el concepto confiere un privilegio caprichoso a favor de la aplicaciön del derecho de quienes tienen un dominio para la provisión de bienes y servicios en transacciones internacionales (JUENGER, Fricdrich K. The UNIDROIT Principles of Commercial Contracts and Inter-American Contract Choice of Law. Contratación Intemacional, Comentarios a los Principios sobre los Contratos Comerciales Internacionales deI UNIDROIT. Universidad Nacional Aukonoma de México. Universidad Panamericana, 1998, p. 229, pp. 206-207). Sobrc las criticas a las solucioncs curopeas, que le han valido calificatives como "laberinto" o "jungla" y, en materia de seguros hasta "infiemo" en cuonto a su regulación (GRUBER, Urs Mcter. Insurance Contracts. Rome I Regulation, The Law Applicable to Contractual Obligations in Europe. Ferrari, Franco. Stefan Leibic. (eds.). Sellier. 2009, p. 110-111), puede verse en BERMAN, Harold J. (nota 10), p. 357; MORRIS, John Humphrey C. The Conflict of Laws. Seventh Edition. David MCCLEAN and Kisch BEEVERS. Sweet \& Maxwell, Thomson REUTERS, 2009, p. 352.

68. CRAiG, LAURENCE, William PARK. JAN PAULSSON. (nota 3), p. 328. La aplicación de las reglas de conflicto directamente elegidas por el ärbitro (método directo, referido más abajo) es otro criterio. pero atendiendo a que éstas deberian ser las percibidas por el árbitro como normas universales o usos concernidos al caso, puede identificarse con el método anterior anterior (CRAIG, LAURENCE, WILLIAM PARK. JAN PAULSSON. (nota 3), pp. 328-329). 
A nivel legislativo las soluciones varian. En Inglaterra, por ejemplo, antes de la Ley de Arbitraje de 1996 se requería que los árbitros aplicaran las reglas de conflicto aceptadas por los tribunales ingleses, en tanto que hoy día existe una remisión amplia a las reglas de conflicto (artículo 46(3). Por su parte, tanto la ley de arbitraje alemana (sección 1051(2) como la ley suiza de arbitraje (artículo 187.1.1) se valen de la regla de conflicto de la "conexión más cercana".

Si bien en este tema la ley modelo (y los cuerpos normativos que la siguen) se atienen a criterios más tradicionales o "conflictualistas", autoridades de peso del mundo arbitral entienden que debe darse una interpretación extensiva a estos instrumentos normativos ${ }^{69}$, que no derive en criterios localistas.

Y aunque así no fuera, la ley modelo contiene una importante disposición de que "en todos los casos, el tribunal arbitral decidirá con arreglo a las estipulaciones del contrato y tendrá en cuenta los usos mercantiles aplicables al caso"70. Como bien lo señala Dalhuisen, la aplicación de este precepto no depende de la voluntad de las partes, y tiene prelación sobre cuanto determinen las reglas de conflicto, en su caso, lo cual da pie a una eventual remisión a la lex mercatorin o el derecho transnacional, al menos en lo que respecta a la aplicación de los principios fundamentales al caso en particular que se presente ${ }^{71}$.

69. Ver en RUIZ ABOU-NIGM. Verónica. (nota 17), p. 117. Incluso, ieyes arbitrales, como las de Francia, Italia y Ilolanda permiten a árbitros aplicar dicha kex aun en ausencia de eleceión de las partes

70. Articulo 28, inciso 4).

71. DALHUISEN, Jan. Dalluisen on Intemational Commercial, Financial and Trade Law. Hart Publishin: 2000, p. 119. Con ello, se sirve mucho mejor a los intereses de las partes. Ya lo señalaba hace varias decadas Gutteridge, que el boicot a los tsibunales, que se hace al recurrirse a los arbitrajes, es el resultado a una inclinación marcada de no correr el riesgo de quedar envueltos en reglas de conflicto tan complicadas que los mereaderes ni sus asesores puedan prever sus efectos. El derecho que prevalecerá ante juzgadores ordinarios puede últimamente estar determinado por un evento puramente fortuito o relativamente trivial, como ocurrio en el famoso caso Vita Food Products Inc. $v$ Unus Shipping Co. (GUTTERIDGE, Harold. Comparative Law, An Introduction to the Comparative Method of Legal Study \& Research. Sccond Edition. Camdridge University Pres: 1949, p. 53) 


\subsection{Método directo}

El método directo, incorporado ahora al artículo 35 del nuevo reglamento de la CNUDMI, es uno de los grandes avances con respecto a las anteriores reglas de 1976, y a la propia ley modelo que, en su artículo 28(2), se remite a normas conflictuales.

De hecho-resalta WEBSTER-no se interpreta como imperativo este artículo de la ley modelo (igual comentario vale para la sección 46 del English Arbitration Act de 1996 que no contempla el método directo), por lo que los árbitros pueden dejar de lado la norma y recurrir al método directo ${ }^{72}$.

Distintos reglamentos de las instituciones arbitrales más relevantes prevén que, ante el silencio de las partes, los árbitros tienen la libertad de elegir el derecho aplicable, y no valerse del mecanismo conflictual para llegar a una legislación local. Un hito a este respecto lo representa el art. 59(a) de las reglas de arbitraje de 1994 del organismo mundial de la propiedad intelectual (WIPO).

En cuanto a la Cámara de Comercio Internacional, hasta 1975 sus reglas arbitrales no contenían una provisión específica de selección del derecho por los árbitros. La tendencia de los árbitros era aplicar el derecho del lugar del arbitraje, que se veía como análoga al foro judicial, cuyas reglas de conflicto prevalecían ${ }^{73}$. Se seguía así una recomendación adoptada en 1957 por Resolución del Instituto de Derecho Internacional. Ello, sin embargo, no se justificaba. Una sede neutral puede, por ejemplo, ser fijada por los árbitros en ausencia de un acuerdo de las partes, en cuyo caso la aplicación de la norma de conflicto de ese lugar puede, además de no llegar a tener conexión con el caso, conducir a un resultado indeseado por los contratantes en cuanto al derecho aplicable ${ }^{74}$.

72. WEBSTER, Thomas H. (nota S), p. 515.

73. CRAIG, Laurence, William PARK, Jan PAULSSON, (nota 3), p. $32 \mathrm{I}$.

74. CRAIG, Laurence, William PARK. Jan PAULSSON. (nota 3), p. 32 t. 
La situación cambió con el artículo 13(3) del reglamento de dicha cámara de 1975, y el nuevo reglamento, de 1998, adopta el método directo. Igual solución siguen el artículo 28.1 del reglamento de la American Arbitration Associntion y el artículo 22(1) de la Cámara de Estocolmo.

En aplicación de este método directo, el árbitro probablemente aplicará también nociones de Derecho internacional privado, al menos en su razonamiento interno, pero -resalta Blessing- sin obligación de dar una explicación o fundamento 75 , a pesar de que sí debe proveer una explicación razonada de su decisión, de acuerdo con las legítimas expectativas de las partes 76

La elección directa no debe, pues, ser vista como arbitraria, $\mathrm{y}$ al efecto pueden tomarse como referencia conceptos que forman parte del sistema conflictual, como la conexión más cercana o el lugar de cumplimiento ${ }^{77}$. Así ocurre por ejemplo cuando se aplica, a las reglas europeas de conflicto, en materia de contratación internacional. El reglamento comunitario conocido como Roma I, si bien no resulta aplicable a los acuerdos para arbitrar como tales, sí puede serlo con respecto a la determinación del derecho sustantivo de los contratos de los que el acuerdo arbitral es parte. De hecho, mucha jurisprudencia ha hecho aplicación del principio de la prestación característica seguido en Europa ${ }^{78}$. También pueden ser tenidas en cuenta las reglas de Roma II (Reg. (EC) No. 864/2007), que contienen la regulación europea de derecho aplicable a obligaciones no contractuales ${ }^{79}$.

75. BLESSING, Marc. (nota 58), p. 12.

76. Señalan DERAINS y SCIIWARTZ que un tribunal arbitral tiene aủn la libertad para aplicar una regla de conflicto, si lo considera apropiado, independientemente de si la regla se origina en un sistema legal nacional, en una convenciön internacional o en los principios generales del derecho internacional privado. Incluso, los ärbitros pueden elaborar su propia regla de conflicto. Sin embargo, cualquiera sea el método que se emplec, los árbitros deben proporcionar una explicación razonada de su decision de acuerdo con las expectalivas legitimas de las partes (DERAINS, Yves, Eric A SCHWARTZ. El Nuevo Regiamento de Arbitraje de la Cámara de Comercio Internacional. Oxford University Press: 2001, p. 274).

77. WEBSTER, Thomas H. (nota 5), p. 515.

78. WEBSTER. Thromas H. (nota 5), pp. 516-518.

79. WEBSTER, Thomas H. (nota 5), pp, 524 y $s$. 


\subsection{Lex mercatoria en ausencia de voluntad de las partes}

Ante su amplia aceptación, se debate si procede también que los árbitros apliquen la lex mercatoria en ausencia de selección del derecho por las partes ${ }^{80}$.

GOODE encuentra varios supuestos en los que un tribunal arbitral podría o debería evitar recurrir a un derecho nacional. Primero: cuando el derecho local eventualmente aplicable se encuentre tan precariamente desarrollado que resulte incapaz de dar solución al asunto. Ello ha sucedido, por ejemplo, en el caso SPP v. Arab Republic of Egypt, en que el tribunal encontró que el derecho islámico (egipcio) no daba respuesta a la cuestión de los intereses. Segundo: cuando los derechos de las partes tengan soluciones opuestas, y el uso de las reglas de conflicto, de por sí, determinaría el resultado de la contienda. En este caso, la lex mecatoria es vista como el método neutral de resolver la disputa, sin herir susceptibilidades del eventual perdedor. Tercero: el derecho de las dos partes o de los Estados con los que el contrato está conectado y la lex mercatoria contienen idéntica solución, con lo que sin tener que declarar un derecho "ganador", el tribunal podría recurrir directamente a la lex mercatoria. Cuarto: las reglas de los sistemas jurídicos en competición son diferentes, y la elección entre un derecho nacional y otro según las reglas de conflicto está tan finamente balanceada que el tribunal encuentra difícil preferir uno del otro, en cuyo caso la referencia a la lex mercatoria puede proveer una salida al problema. Quinto: la elección de un sistema jurídico nacional es vista por el tribunal arbitral como insatisfactoria, porque envuelve la aplicación a una transacción internacional de una ley nacional dirigida al comercio doméstico. Sexto: al tribunal simplemente no le gusta la ley aplicable del derecho nacional, o el resultado que produciría, y está determinado a encontrar el método de evitarlo. Siente el tribunal que está casado al concepto de la lex mercatoria y desea asirlo cada oportunidad que tiene para aplicarlo y expandir su influencia ${ }^{81}$.

80. Además de cuestiones relativas a las fucntes y a metodologia RUIZ ABOU-NIGM, Verónica. (nota 17), p. 105. 
Está visto que, en principio, la ley modelo permite a los árbitros aplicar reglas no nacionales solo cuando las partes las han elegido como aplicables a la sustancia. Expresa Mustill -en un comentario extensivo al artículo 35 del nuevo reglamento- que la decisión consciente de los que elaboraron la ley modelo de la CNUDMI, al emplear en el artículo 28(2) la palabra "ley" en vez de "reglas de derecho", debe haber sido una gran desilusión para los "lex-mercatoristas" y constituirá un serio obstáculo para el crecimiento de lex ${ }^{82}$.

Sin embargo, la creciente casuística a partir de este comentario (emitido en 1987) indica todo lo contrario ${ }^{83}$. De allí que deba darse la razón a Blessing, por ejemplo, respetada autoridad en la materia, quien aboga por una interpretación extensiva a estos cuerpos normativos. También hacen lo propio otras renombradas figuras mundiales del arbitraje de hoy, como, por ejemplo, Gaillard 84 .

Es de lamentar que el nuevo reglamento no haya admitido abiertamente la aplicabilidad de la lex mercatoria en estos supuestos de ausencia de elección, en línea con principales reglamentos arbitrales y leyes de vanguardia en la materia ${ }^{85}$.

81. GOODE. Roy. (nota II), p. 31.

82. MUSTILL, Lord Justice. (nota 6), p. 181.

83. La aplicación de principios intemacionales, como los de UNIDROIT y PECL aumenta día a dia, y tiene la ventaja que, entre otras, cosas el tribunal arbitral puede evitar el especifico e inicial problema de determinar el derecho aplicable conforme al Derecho internacional privado (Communication on European Contract Law: Joint Response of the Comision on Europcan Contract Law and the Study Group on a European Civil Code (www.sgecenet), p. 17)

84. Ver RUiz ABOU-NIGM, Verónica, (nota 17), p. 117.

85. Este énfasis lo pongo luego de comentarios recibidos del ilustre colega Alfredo De Jesús $O$., quien resalta la clara regresión del nuevo articulo 35 en este punto. Se elimina el sistema conflictual pero, sin embargo, pareciera mantenerse la imposición de un derecho nacional. Si esto es asi-observa De Jesús-el nucvo Articulo 35 refleja una lamentable regresión que para nada se compagina con ias mejores prácticas (recogidas en los reglamentos de instituciones arbitrales preponderantes) que le dan la libertad al airbitro para aplicar "las normas que estime apropiadas" en caso de falta de indicación de las partes sobre el derecho aplicable al fondo. Si esto en verdad es asi, podria incluso decirse que muy probablemente sea una consecuencia lamentable de la preparación de textos internacionales a través de consensos. Quizás la búsqueda de consensos impidió nuevamente, al igual de lo que ocumió con la ley modelo, que la CNUDMt adopte en este tema una posición de vanguardia. 
En Francia y Holanda, por ejemplo, las leyes arbitrales permiten que los árbitros apliquen dicha lex aun en ausencia de elección de las partes ${ }^{86}$. Bajo influencia de las reformas francesas de ya hace unas décadas, e ideas de Pieter SANDERS sobre la lex mercatoria, el artículo 1054 de la ley de arbitraje de Holanda está fraseado de igual manera que su precedente francés. El reporte explicativo a la ley holandesa confirmó explícitamente que los árbitros, en casos intencionales, pueden aplicar la lex mercatoria, en tanto hayan sido autorizados por las partes o en ausencia de elección. Incluso, el reporte holandés sigue a Goldman en la definición de la lex mercatoria ${ }^{87}$.

Por su parte, la sección 46 (1) (b) de la ley inglesa de arbitraje de 1966 dispone que si los contratantes así lo admiten, el tribunal arbitral resolverá el asunto de acuerdo a aquellas otras consideraciones (distintas a la ley) que hayan acordado las partes o que decida el tribunal. Notas explicativas al proyecto de 1985, redactadas por un comité consultivo departamental de arbitraje, decían que esa sección corresponde el artículo 28 de la ley mode$10^{88}$.

A su vez, el flamantemente sancionado nuevo artículo 1511 del código procesal civil francés, dispone que el tribunal arbitral podría decidir el litigio de conformidad a las normas de derecho que las partes han elegido o, en su defecto, de acuerdo a aquellas que estime apropiadas, debiendo tener en cuenta, en todos los casos, los usos de comercio ${ }^{89}$. El reporte explicativo enfatiza que el artículo 1511 y otros relacionados, consagran la existencia de un orden jurídico autónomo en materia de arbitraje internacional $^{90}$.

86. RUIZ ABOU-NIGM, Verónica, (nota 17), p. 117. El comentario, emitido con relación a la anterior ley francesa, es válido con respecto a la actual.

87. DE LY, Filip. (nota 95), p. 250.

88. Department of Trade and industry, Consultative paper, secc. 1 y 2: Draft Clauses of an Arbitration Bill. p. 38). (Notas, art. 1:101 PECL, comentario 3, a)

89. El art. $1496 \mathrm{del}$ Código Procesal Francés otorga la facultad de que los árbitros apliquen la kex mercatoria: esto se desprende también del articulo 1700 del Código Procesal Civil Belga; del artículo 1496 del Código Procesal Francés; del articulo 1054 del Código Procesal llolandés; y del articulo 834 del Código Procesal Civil ltaliano. 
Se ha advertido que si los árbitros tienen dudas sobre la aceptación de la lex mercatoria por las partes, tendrían que intentar acomodarse a su voluntad y dar debida consideración a leyes domésticas relevantes. $\mathrm{Si}$ es posible, el laudo debería dejar en claro que la aplicación de la lex mercatoria no lleva a resultados incompatibles con sistema doméstico alguno de eventual aplicación, o que el derecho nacional indicado por las reglas conflictuales no se contradice con la lex mercatoria referida en la cláusula arbitral91.

Como bien lo señala GOODE, los tribunales arbitrales tienen un deber moral y jurídico de actuar en una forma disciplinada y de acuerdo a principios establecidos, al menos que estén dispensados por acuerdo de partes ${ }^{92}$.

\subsection{Ex aequo et bono y amiable composition}

Si bien hay disparidades terminológicas en distintos sistemas ${ }^{93}$, con estas expresiones se hace alusión al arbitraje de equidad, previsto en el artículo 28 de la ley modelo y en varios reglamentos arbitrales ${ }^{94}$.

Los árbitros deben mostrarse sumamente cautos a este respecto. Los tribunales franceses, por ejemplo, han resuelto que en arbitrajes de equidad, los árbitros deben dar razones para justi-

90. Hace ya varios años GOLDMAN habia scrialado, en sus clases ante la Academia de La Haya de Derecho Internacional Privado, que era necesario desarrollar reglas autónomas de conflicto para arbitrajes comerciales internacionales a fin de evitar resultados no satisfactorios emergentes de la aplicaciön de las reglas de conflicto del Estado sede el arbitraje y del Estado cuyas leyes resultan aplicables a los méritos de la dispula. Asimismo, reglas de conflicto autónomas serian necesarias en arbitrajes en que la /ex mercatoria se aplicaria a la sustancia de la disputa, aboganco por un sistema arbitral de conflicto autónomo (DE LY, Filip. (nota 11), pp. 212-213).

91. CARON, David, Lee M CAPLAN, Matti PELLONPẢÄ. (nota 31), p. 129. En términos análogos formulan una advertencia CRAIG, PARK y PAULSSON (CRAIG, Laurence, William PARK, Jan PAULSSON. (nota 3), p. 337).

92. GOODE, Roy. (nota II), p. 7.

93. CARON, David, Lee M CAPLAN, Matti PELLONPÄÄ. (nota 15), p. 134.

94. Con ello se quiere significar que el tribunal puede basarse en consideraciones de equidad y justicia, aunque la palabra "equity" no debe entenderse en la acepeión especifica que tiene en las jurisdicciones del common law, WEBSTER, Thomas H. (nota 5), p. 528. 
ficar su decisión, sin que les esté permitido simplemente aplicar un derecho. Recientemente, en el caso Fotovista, la Corte de Apelaciones de París anuló un laudo basado en amiable composition porque el árbitro no explicó su decisión de aplicar el derecho francés en las catorce páginas del laudo ${ }^{95}$.

Demás está decir que considerar los términos del contrato y los usos debería ser parte de la evaluación acerca de qué es equitativo en arbitrajes de equidad ${ }^{96}$, puesto que, como lo señalan la ley modelo y el reglamento, aquellos deben ser tenidos en cuenta en todos los casos $^{97}$.

Decidir en equidad es una facultad pero no una obligación de los árbitros. Estos pueden tener razones para aplicar de todos modos un derecho determinado, cuando podría haber peligro de invalidación o de no reconocimiento en jurisdicciones que no admitan el arbitraje de equidad, o cuando ello contradiga términos claros del contrato ${ }^{98}$.

\subsection{Usos mercantiles aplicables al caso}

El artículo 28, inciso 4) de la ley modelo, así como el artículo 35 del reglamento de la CNUDMI, prevén que deben atenderse, en todos los supuestos, las estipulaciones del contrato, si las hubiera, y tenerse en cuenta "los usos mercantiles aplicables al caso" 99 .

95. CA Paris, Encro 15, 2004, Sociét Centrale Fotovista v Vanoverbeke et al. (2004), citado por WEBSTER. Thomas H. (nota 5), p. 528.

96. WEBSTER, Thomas H. (nola 5), p. 529.

97. La nueva lex mercatoria tuvo un particular desarrollo en casos en que los árbitros podian actuar ex acquo et bone o como amiables compositeurs. Los árbitros sinticron que, aunque no estuvicran atados por reglas estrictas, sus laudos debian de todos modos basarse en principios razonables, de modo que aunque son conecptos diferentes, la lex mercatoria emergió como consecuencis de esa facultad de laudar en cquidad (RUIZ ABOU-NIGM, Verónica. (nota 17), p. 108). David rechaza, por no corresponder a la práctica y por carecer de fundamento desde el punto de vista de les principios, la distinción entre el arbitraje de derecho y el arbitraje en equidad, en el entendimiento de que ta equidad no es una alternativa sino un progreso del derecho (ver en OPPETIT, Bruno. Teoria del Arbitraje. Traducido por: Eduardo Silva Romero, Fabricio Mantilla Espinoza y Josć Joaquin Caicedo Demoulin. Legis Editores, 2006, pp. 278-279, nota al pic).

98. CARON, David, Lee M CAPLAN, Mati PELLONPÄÄ. (nota I5), p. 136. 
Ya la Convención Europea de Arbitraje Comercial Internacional de 1961 preveía en su Artículo VII que en todos los casos los árbitros deben tomar en consideración los "términos del contrato y los usos de comercio". Esto fue calificado por Blessing como uno de los más significantes acontecimientos del siglo XX, al liberar el arbitraje de percepciones locales ${ }^{100}$.

En la misma senda, el reglamento de la Cámara de Comercio Internacional dispone en su art. 17(2) que "en todos los casos el Tribunal Arbitral deber tener en cuenta la previsión contractual $\mathrm{y}$ todo uso relevante de comercio". Cuando esta regla fue formulada en 1975, el entonces Vice-Chairman de la Corte, Jean Robert, dijo: "Es legítimo pensar aqui que esa fórmula abre camino a una forma de arbitraje más o menos libre, en el futuro, de constreñinientos legalísticos"101.

Señala David que el acuerdo de las partes para arbitrar disputas que surjan de un contrato internacional implica que, además de cualquier estipulación expresada en el convenio, serán tenidas también en cuenta los usos de la comunidad de comerciantes internacionales que resulten aplicables. Esta autoridad jurisdiccional implícita no es ni antiable composition (arbitraje de equidad) ni fallo acorde con la ley en su acepción usual. En vez,

99. El articulo 1054 de la ley procesal holandesa sigue la ley modelo de la CNUDMI sin describir claramente qué quieren decir con usos del comercio. El comentario oficial holandés referia a la lex mercatoria en estc contexto y permitia su aplicación, sin discutir exactamente qué era (DALHUISEN, Jan. (nota 95), p. 119).

100. BLESSING, Marc. (nota 57), p. 12. Más recientemente, la Convención de México prevé que se tomarin en cuenta "los principios generales del derecho comercial internacional aceptados por organismos internacionales" (Articuło $9^{\circ}$, prirrafo segundo), y señala, además, que tendrán aplicación, cuando corresponda, "las normas, las costumbres y los principios del derecho comercial internacional, asi como los usos y prácticas comerciales de general aceptación con la finalidad de realizar las cxigencias impuestas por la justicia y la equidad en la solución del caso concreto" (articulo 10), Sobre el alcance $y$ las consecuencias fecundas de estos articulos, ver MORENO RODRIGUEZ, José A. (nota 7).

101. Los requerimientos del articulo $17(2)$ pueden ser vistos tanto como complemento a una previsión del derecho nacional sustantivo determinado a ser aplicable al contrato, como también como sustituto de la aplicación de un derecho nacional sustantivo. Aun cuando los árbitros han determinado que una sola ley nacional gobiema la interpretación y cjecución del contrato en cuestión, térninos especificos del contrato tienden a adquirir prevalencia sobre principios de derecho establecidos en leyes o fallos judiciales, salvo una expresa provisión legal de efecto obligatorio, por ejemplo relativa al ejercicio del poder estatal (CRAIG, LAUREnCE. WILLIAM PARK, JAN PAULSSON. (nota 3), p. 331). 
demuestra que un marco de resolución de disputas, especialmente creado e innovador, se aplica en el arbitraje comercial internacional102. Las reglas de buena conducta comercial, precisamente porque son amplias y adaptables, dan a los árbitros una guía mejor y más apropiada que distinciones técnicas de disposiciones legales rígidas, lo cual constituye el sello de la legislación local ${ }^{103}$.

\section{Conclusión}

Las vinculaciones comerciales transfronterizas encuentran en el arbitraje un mecanismo normalmente más apropiado para que sean atendidos tanto las expectativas de las partes como los requerimientos de justicia que demandan este tipo de contratos, acorde con la atmósfera cosmopolita en que se desarrollan.

Al respecto, esta contribución ha abordado distintas cuestiones que son claves para un entendimiento de las concepciones actuales preponderantes, cuya conclusión no puede ser otra que la ya adelantada, es decir, que el arbitraje debería permitir liberar la contratación internacional de constreñimientos legalistas inapropiados. Estas vinculaciones requieren ser consideradas desde el prisma transfronterizo en que se llevan adelante, para así servirse apropiadamente a las partes envueltas y, en general, al comercio internacional en sí, que de esta forma se puede desarrollar de manera mucho más apta que con la aplicación de rígidas reglas domésticas, no infrecuentemente inadecuadas para tal fin.

102. Ver en CARBONNEAU, Tom. A Definition and Perspective Upon the Lex Mercatoria Debate. Lex Mercatoria and Arbitration, A Discussion of the New Lew Merchant. Revised Edition. CARBONNEAU, Thomas E. (ed.). Jurts Publishing, Kluwer Intemational Law: 1998, p. 21.

103. CARBONNEAU, Thomas. (nota anterior), p. 37. 